\title{
Neonatal inflammatory skin and bowel disease
}

INSERM

\section{Source}

INSERM. (1999). Orphanet: an online rare disease and orphan drug data base. Neonatal inflammatory skin and bowel disease. ORPHA:294023

Neonatal inflammatory skin and bowel disease is a rare, life-threatening, autoinflammatory syndrome with immune deficiency disorder characterized by earlyonset, life-long inflammation, affecting the skin and bowel, associated with recurrent infections. Patients present perioral and perianal psoriasiform erythema and papular eruption with pustules, failure to thrive associated with chronic malabsorptive diarrhea, intercurrent gastrointestinal infections and feeding troubles, as well as absent, short or broken hair and trichomegaly. Recurrent cutaneous and pulmonary infections lead to recurrent blepharitis, otitis externa and bronchiolitis. 